\title{
In vitro characterization of a synthetic calcium phosphate bone graft on periodontal ligament cell and osteoblast behavior and its combination with an enamel matrix derivative
}

\author{
Richard J. Miron • Dieter D. Bosshardt • \\ Anja C. Gemperli • Michel Dard • Daniel Buser • \\ Reinhard Gruber • Anton Sculean
}

Received: 11 September 2012 / Accepted: 4 April 2013 / Published online: 26 April 2013

(C) Springer-Verlag Berlin Heidelberg 2013

\begin{abstract}
Objectives Recent studies suggest that a combination of enamel matrix derivative (EMD) with grafting material may improve periodontal wound healing/regeneration. Newly developed calcium phosphate $(\mathrm{CaP})$ ceramics have been demonstrated a viable synthetic replacement option for bone grafting filler materials.

Aims This study aims to test the ability for EMD to adsorb to the surface of $\mathrm{CaP}$ particles and to determine the effect of EMD on downstream cellular pathways such as adhesion, proliferation, and differentiation of primary human osteoblasts and periodontal ligament (PDL) cells.

Materials and methods EMD was adsorbed onto CaP particles and analyzed for protein adsorption patterns via scanning electron microscopy and high-resolution immunocytochemistry with an anti-EMD antibody. Cell attachment and cell proliferation were quantified using CellTiter 96 One Solution Cell Assay (MTS). Cell differentiation was analyzed using real-time PCR for genes encoding Runx2, alkaline phosphatase, osteocalcin, and collagen $1 \alpha 1$, and mineralization was assessed using alizarin red staining.
\end{abstract}

R. J. Miron · D. D. Bosshardt · R. Gruber · A. Sculean $(\bowtie)$ Department of Periodontology, School of Dental Medicine, University of Bern, Freiburgstrasse 7,

3010 Bern, Switzerland

e-mail: anton.sculean@zmk.unibe.ch

R. J. Miron · D. D. Bosshardt · D. Buser $\cdot$ R. Gruber Department of Oral Surgery and Stomatology, School of Dental Medicine, University of Bern, Freiburgstrasse 7,

3010 Bern, Switzerland

\author{
A. C. Gemperli • M. Dard \\ Institute Straumann AG, Basel, Switzerland
}

Results Analysis of cell attachment revealed significantly higher number of cells attached to EMD-adsorbed $\mathrm{CaP}$ particles when compared to control and blood-adsorbed samples. EMD also significantly increased cell proliferation at 3 and 5 days post-seeding. Moreover, there were significantly higher mRNA levels of osteoblast differentiation markers including collagen $1 \alpha 1$, alkaline phosphatase, and osteocalcin in osteoblasts and PDL cells cultured on EMDadsorbed $\mathrm{CaP}$ particles at various time points.

Conclusion The present study suggests that the addition of EMD to CaP grafting particles may influence periodontal regeneration by stimulating PDL cell and osteoblast attachment, proliferation, and differentiation. Future in vivo and clinical studies are required to confirm these findings.

Clinical relevance The combination of EMD and CaP may represent an option for regenerative periodontal therapy in advanced intrabony defects.

Keywords Enamel matrix derivative (EMD) - Emdogain · Allograft $\cdot$ Blood proteins $\cdot$ Protein adsorption $\cdot$ Bone grafting materials

\section{Introduction}

Over the past 20 years, significant progress has been made in the development of new bone grafts and bone substitute materials for the treatment of bony defects [1]. Bone grafts are commonly used in oral surgeries to fill voids, augment bone, facilitate or enhance bone repair, provide mechanical membrane support, stabilize blood clots, and serve as a vehicle for antibiotics and growth factors. Although autogenous bone grafts are considered the gold standard, a variety of biological and synthetic materials, including bone allografts (freeze dried 
from human donors), xenografts (from animals or plants), and alloplasts (synthetically fabricated such as hydroxyapatite, beta tricalcium phosphate, biphasic calcium phosphate, polymers and bioactive glass), are extensively being studied [2-5] in order to avoid the drawbacks and limitations of autogenous bone which include donor site morbidity and increased surgical costs.

In order to improve the osteoconductive properties of synthetic bone grafts, recent attempts at combining alloplasts with autogenous bone or growth factors have been utilized to establish osteoinductive capacity [1, 6-9]. Nevertheless, the inability to harvest large quantities of autogenous bone and the large expenses and short half-lives of growth factors still pose a clinical challenge [10]. Yuan et al. were one of the first to show that different synthetic biomaterials were able to induce ectopic bone formation in various animal models, and further studies have reconfirmed these observations [11]. Recently, a calcium phosphate $(\mathrm{CaP})$ ceramic sintered at low temperatures was implanted in dogs and sheep and demonstrated as effective as autologous bone in treating bone defects $[12,13]$. Bone induction by $\mathrm{CaP}$, although shown in some studies, is in general not the standard mode of action for the large majority of $\mathrm{CaP}$ products.

Similarly, the use of an enamel matrix derivative (EMD) composed primarily of amelogenin proteins has successfully been utilized for its ability to regenerate periodontal tissues including cementum, periodontal ligament, and bone [14]. Although histological and controlled clinical studies have provided evidence for periodontal regeneration and substantial clinical improvements following the use of EMD in intrabony defects [14], concerns have been expressed regarding the viscous nature of EMD, which may not be sufficient to prevent flap collapse in periodontal defects with a complicated anatomy thus limiting the amount of space available for periodontal regeneration $[15,16]$. In order to overcome this potential limitation and improve the clinical results obtained with EMD, recent attempts at combining various types of grafting materials with EMD have been investigated $[5,17-30]$. While the majority of clinical [17, 21, 22, 25-28] and animal studies [20, $23,24]$ reveal a potential benefit for a combination approach, others have failed to demonstrate an advantage $[5,18,19,29,30]$.

Therefore, the aim of the present study was to assess the ability for a particular $\mathrm{CaP}$ bone ceramic to support osteoblast and periodontal ligament (PDL) cell attachment, proliferation, and differentiation on their surfaces. Furthermore, the ability for EMD to adsorb to the surface of $\mathrm{CaP}$ particles as well as influence cell behavior will be compared to a control and blood-adsorbed samples.

\section{Materials and methods}

Scanning electron microscopy

Scanning electron microscopy (SEM) was used to visualize the surface topographies of $\mathrm{CaP}$ particles (Institut Straumann AG, Basel, Switzerland) adsorbed with blood and EMD (Emdogain, Institut Straumann AG, Basel, Switzerland) or left unaltered (control). CaP particles were fixed in $1 \%$ glutaraldehyde and $1 \%$ formaldehyde. Following dehydration with ethanol, samples were critical point dried (Type M.9202, Critical Point Dryer, Roth \& Co., Hatfield, PA, USA) followed by overnight drying. Next, samples were sputter coated (DCM-010, Balzers, Liechtenstein) with a 10-nm layer of gold and analyzed microscopically using a scanning electron microscope (XL30 FEG, Philips, Eindhoven, Netherlands) to determine surface variations between samples.

\section{Histologic processing}

In order to determine the ability for EMD to adsorb and penetrate into $\mathrm{CaP}$ particles, $\mathrm{CaP}$ particles $+\mathrm{EMD}$ were fixed in $1 \%$ glutaraldehyde and $1 \%$ formaldehyde, buffered with $0.08 \mathrm{M}$ sodium cacodylate ( $\mathrm{pH}$ 7.4). The samples were then washed in $0.1 \mathrm{M}$ sodium cacodylate

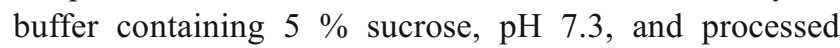
for embedding in LR White resin (Fluka, Buchs, Switzerland). Semithin LR White survey sections (1 $\mu \mathrm{m}$ thick) were cut with glass and diamond knives on a Reichert Ultracut E microtome (Leica Microsystems, Glattbrugg, Switzerland), stained with toluidine blue and basic fuchsin, and observed in a Zeiss Axioplan microscope (Carl Zeiss, Gottingen, Germany).

\section{High-resolution immunocytochemistry}

The high-resolution protein A-gold technique was used for the immunocytochemical localization of EMD to determine the ability for EMD to adsorb the surface and penetrate $\mathrm{CaP}$ particles as previously described [31]. Thin $(80-100 \mathrm{~nm})$ sections of LR Whiteembedded tissues were cut with a diamond knife, mounted on formvar- and carbon-coated nickel grids, and then floated on a drop of $0.01 \mathrm{M}$ phosphatebuffered saline (PBS), $\mathrm{pH} 7.3$, containing $1 \%$ ovalbumin (Fluka, Buchs, Switzerland) in order to saturate nonspecific binding sites. Sections were transferred and incubated for $1 \mathrm{~h}$ on a drop of affinity-purified rabbit anti-EMD polyclonal antibody [31] diluted with PBS. Following incubation with the primary antibody, the grids were rinsed with PBS, floated on $1 \%$ ovalbumin in PBS for $10 \mathrm{~min}$, and then incubated for $30 \mathrm{~min}$ with 
protein A-gold complex prepared with gold particles of approximately $10 \mathrm{~nm}$ (Drs. G Posthuma and J.W. Slots, University Medical Center Utrecht, Utrecht, Netherlands). Thereafter, the grids were washed with PBS and distilled water, contrasted with uranyl acetate and lead citrate, and examined in a Philips 300 transmission electron microscope operated at an accelerating voltage of $60 \mathrm{kV}$.

EMD adsorption to bone grafting particles for in vitro experiments

EMD was prepared according to Institut Straumann AG standard operating protocols as previously described [31]. Thirty milligrams of EMD was dissolved in $3 \mathrm{ml}$ of sterile $0.1 \%$ acetic acid at $4{ }^{\circ} \mathrm{C}$. For experiments, stock EMD was diluted $100 \times$ in $0.1 \mathrm{M}$ carbonate buffer at $4{ }^{\circ} \mathrm{C}$ to a working concentration of $100 \mu \mathrm{g} / \mathrm{ml}$. One milliliter of EMD solution was incubated overnight at $4{ }^{\circ} \mathrm{C}$ into 24 -well culture dishes containing $100 \mathrm{mg}$ of CaP particles (Institut Straumann, AG, Basel, Switzerland). Following incubation, dishes were rinsed twice with $1 \mathrm{ml}$ PBS.

\section{Osteoblast and PDL cell isolation and differentiation}

Human bone chips were cultured according to an explant model under a protocol approved by the Ethics Committee, Katon Bern, Switzerland. PDL cells were obtained from the middle third portion of three teeth extracted from healthy patients with no signs of periodontal diseases at the Department of Orthodontics, Dental Clinic, University of Bern, as previously described [31]. Primary human osteoblasts and PDL cells were detached from the tissue culture plastic using trypsin solution (Invitrogen, Basel, Switzerland). Cells used for experimental seeding were from passages 4-6. Primary osteoblasts and PDL cells were separately seeded at a density of 10,000 cells into their respective 24 well culture plates for cell attachment and cell proliferation experiments and 50,000 cells for real-time PCR and alizarin red experiments. For experiments lasting longer than 5 days, the medium was replaced twice weekly.

Adhesion and proliferation assays

Primary osteoblasts and PDL cells were quantified using the CellTiter 96 One Solution Cell Assay (MTS; Promega, Madison, WI, USA) as previously described [32]. Cells were seeded on $100 \mathrm{mg}$ of $\mathrm{CaP}$ per well in 24 -well plates at a density of 10,000 cells per well. At 4 and $8 \mathrm{~h}$ for cell adhesion and 1,2,3, and 5 days for cell proliferation, cells were washed with PBS incubated with $80 \mu \mathrm{l}$ of CellTiter96 aqueous solution dissolved in $400 \mu \mathrm{l}$ of PBS. After $4 \mathrm{~h}$ of culture, the cell viability was determined by measuring the absorbance at $490 \mathrm{~nm}$ on a 96-well plate reader. Experiments were performed in triplicate with three independent experiments for each condition. Data $( \pm \mathrm{SE})$ were normalized to control samples.

\section{Real-time RT-PCR}

Real-time RT-PCR was employed to quantify the total RNA of PDL cell and osteoblast-related differentiation markers. Total RNA was isolated using TRIZOL reagent and RNAeasy Mini kit (Qiagen, Basel, Switzerland) at 3, 7, and 14 days of osteoblast differentiation markers. Primer and probe sequences for genes encoding alkaline phosphatase (ALP, Hs01029144_m1), runt-related transcription factor 2 (Runx2, Hs00231692_m1), collagen $1 \alpha 1$ (COL1A1, Hs01028970_m1), osteocalcin (OC, Hs01587814_g1), and glyceraldehyde 3-phosphate dehydrogenase (GAPDH, Hs03929097_g1) were purchased as predesigned gene expression assays (Taqman, Applied Biosystems, Rotkreuz, Switzerland). Real-time RT-PCR was performed using $20 \mu \mathrm{l}$ final reaction volume of One step Master Mix kit as previously described [33]. RNA quantification was performed using a Nanodrop $2000 \mathrm{c}$, and $100 \mathrm{ng}$ of total RNA was used per sample well. All samples were assayed in triplicate, and three independent experiments were performed. The $\Delta \Delta \mathrm{Ct}$ method was used to calculate gene expression levels normalized to GAPDH values and calibrated to control $\mathrm{CaP}$ particles. Data were log-transformed prior to analysis by two-way ANOVA with Bonferroni test using Graphpad Software v. 4 (La Jolla, CA, USA).

\section{Alizarin red quantification}

Alizarin red staining was performed to determine the presence of extracellular matrix mineralization after 21 days. Osteoblasts were seeded at a density of 50,000 cells per 24-well culture dish onto control, blood-adsorbed, and EMD-adsorbed CaP particles. After 21 days, cells were fixed in $96 \%$ ethanol for $15 \mathrm{~min}$ and stained with $0.2 \%$ alizarin red solution (Sigma-Aldrich, Basel, Switzerland) in water ( $\mathrm{pH}$ 6.4) at room temperature for $1 \mathrm{~h}$. Samples representing background staining $(\mathrm{CaP}$ particles without cells) were treated identically. Alizarin red was dissolved using a solution of $20 \%$ methanol and $10 \%$ acetic acid in water for $15 \mathrm{~min}$. Liquid was then transferred to cuvettes and read on a spectrophotometer at a wavelength of $450 \mathrm{~nm}$ as previously described [34]. After subtraction of background, absorbance values were 
Fig. 1 SEM images of $\mathrm{CaP}$ particles. $(A-C)$ Control $\mathrm{CaP}$ particles. $(D-F)$ Adsorption of blood to CaP particles. $(G-I)$ Adsorption of EMD to $\mathrm{CaP}$ particles
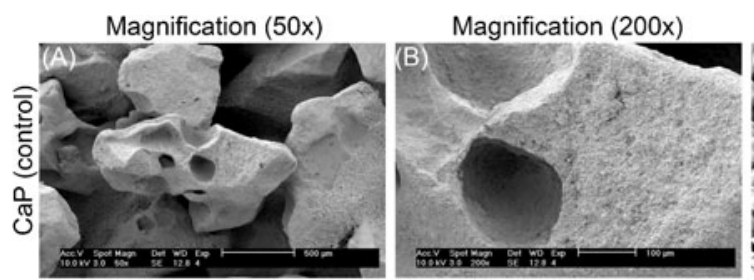

Magnification (6400x)
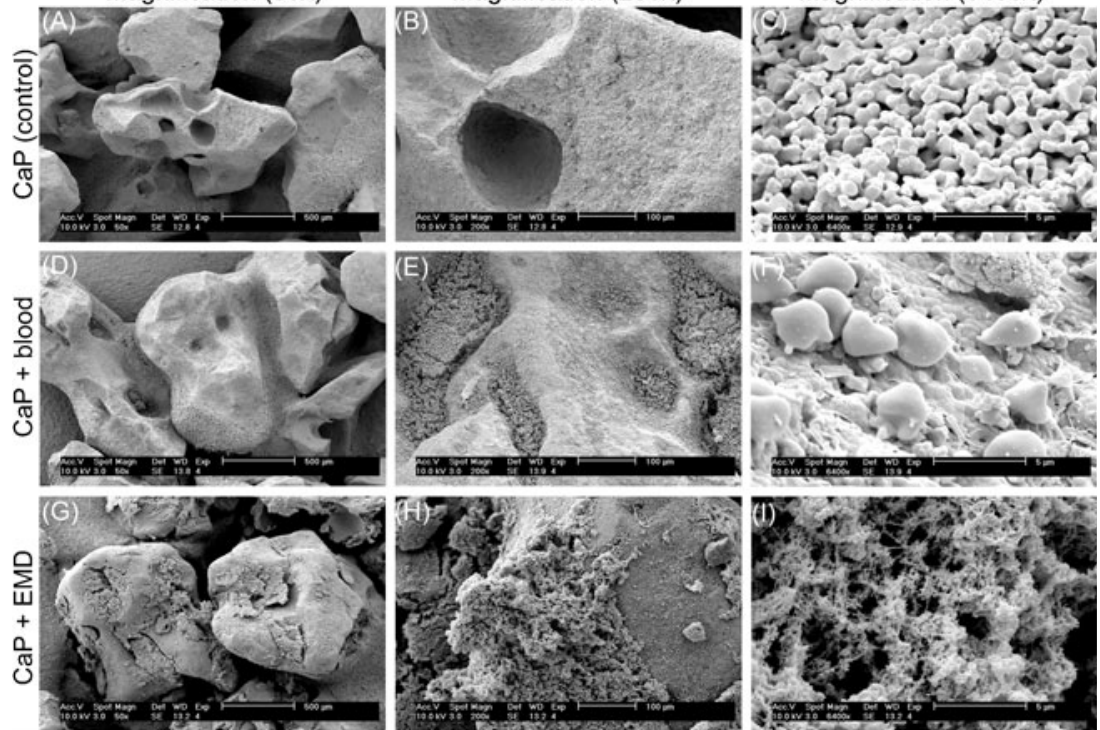

normalized to DNA content. Data were analyzed for statistical significance using one-way analysis of variance with Tukey's test.

\section{Results}

\section{Scanning electron microscopy}

Control CaP particles varied in micro and macro topographies on the surface of grafting particles with the odd interconnected pore observed within a graft particle (Fig. 1(A, B)). The high-resolution SEM images demonstrated an extremely rough surface with many variations in surface nanotopographies (Fig. 1(C)). Surface adsorption with blood revealed strong attachment of red blood cells (RBCs) and a fibrin matrix to the surface of $\mathrm{CaP}$ particles (Fig. 1(D)). The accumulation of hundreds of RBCs can be observed at magnification $\times 200$ (Fig. 1(E)). Interestingly, RBCs demonstrate variable affinity to the surface of $\mathrm{CaP}$ particles with certain graft regions being preferentially covered (Fig. 1(E)). At high magnification $(\times 6,400)$, a fibrin/protein network surrounding RBCs could be observed with many of the nanotopographies present in the control sample no longer visible (Fig. 1 (F)). The effect of surface adsorption with EMD revealed substantial protein deposition on the surface of $\mathrm{CaP}$ particles (Fig. 1(G)). Despite widespread protein attachment, inhomogeneity of EMD adsorption was observed (Fig. 1(H)). High-resolution images revealed a network of EMD protein fibers spanning over the surface of $\mathrm{CaP}$ particles with variable protein density covering the surface (Fig. 1(I)).
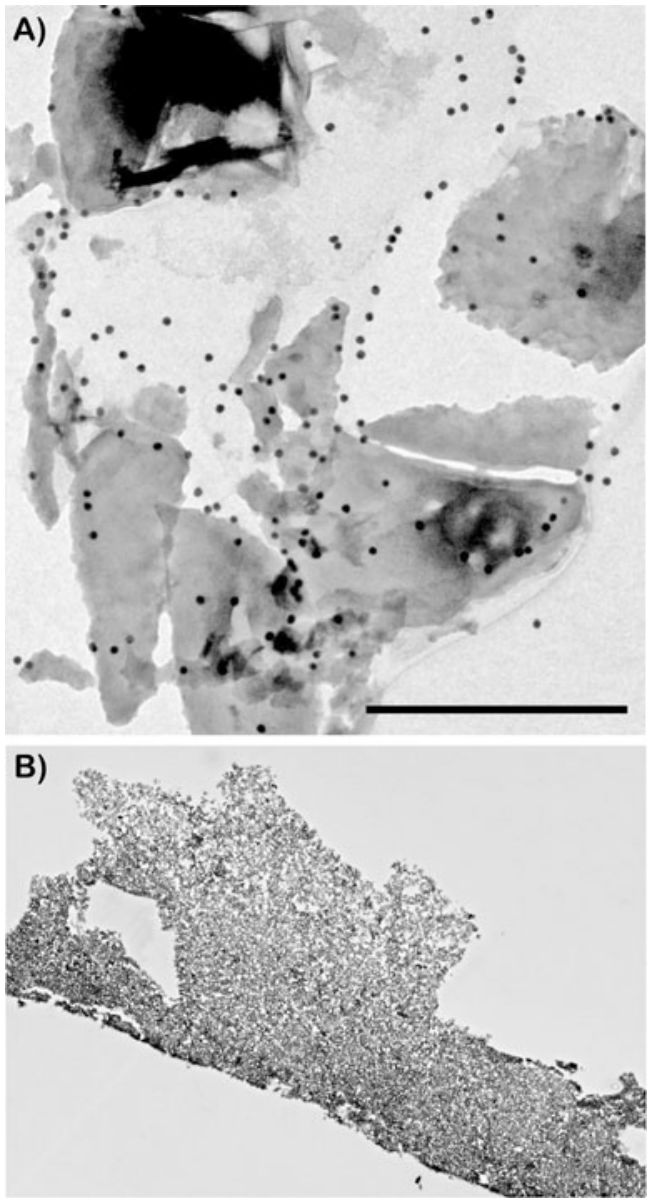

Fig. 2 TEM images demonstrating adsorption of EMD to CaP particles to the exterior of grafting material. a Particles were extensively labeled with an anti-EMD antibody with staining observed around the grafting particles. Little to no penetration was observed in the interior of $\mathrm{CaP}$ particles $($ bar $=0.5 \mu \mathrm{m})$. b No labeling was observed on control $\mathrm{CaP}$ particles that were not treated with EMD 


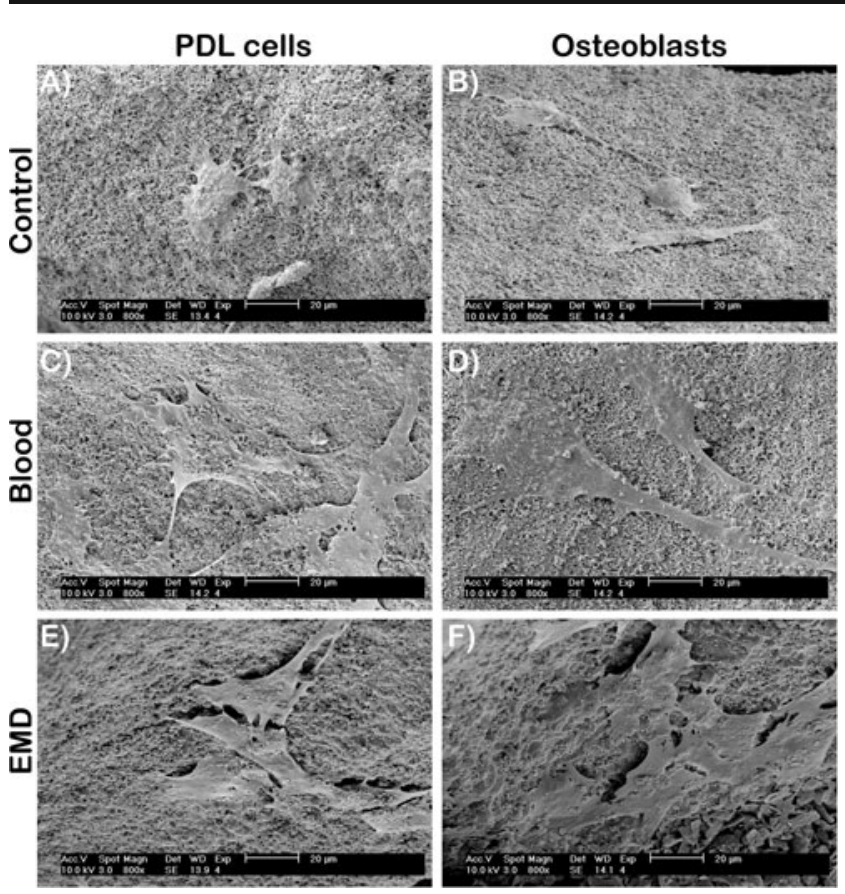

Fig. 3 SEM images of primary human osteoblasts $(A, C, E)$ and PDL cells $(B, D, F)$ on CaP particles $8 \mathrm{~h}$ post-seeding. All cells attached well on control, blood-adsorbed, and EMD-adsorbed CaP particles

\section{Transmission electron microscopy}

High-resolution immunohistochemistry was then performed using gold labeling for an anti-EMD antibody to determine the ability for EMD to adsorb and penetrate into $\mathrm{CaP}$ grafting particles (Fig. 2). CaP particles pre-adsorbed with EMD stained positively for anti-EMD at the surface of $\mathrm{CaP}$ particles. Gold labeling was rarely present on the interior of $\mathrm{CaP}$ particles demonstrating an inability for EMD proteins to penetrate to the interior regions of grafting particles.

\section{Osteoblast and PDL cell attachment and proliferation}

In order to demonstrate cell compatibility with $\mathrm{CaP}$ particles, primary human osteoblasts and PDL cells were observed via SEM $24 \mathrm{~h}$ following post-seeding (Fig. 3). Osteoblasts and PDL cells attached on all control, bloodadsorbed, and EMD-adsorbed CAP particles (Fig. 3). Cells seeded on EMD initially demonstrated a greater ability to attach and spread on $\mathrm{CaP}$ grafting particles (Fig. 3(E, F)). Analysis of MTS cell number revealed significantly higher osteoblast and PDL cell number at 4 and $8 \mathrm{~h}$ post-seeding on EMD-adsorbed $\mathrm{CaP}$ particles when compared to blood-adsorbed and control surfaces (Fig. 4a, b). At $24 \mathrm{~h}$ post-seeding, cell number approached $100 \%$ cell attachment levels for all treatment modalities (Fig. 4a, b). EMD displayed a significant increase on cell proliferation for both PDL cells (Fig. 5c) and osteoblasts (Fig. 5d) at 3 and 5 days postseeding. Interestingly, EMD had a more pronounced effect on PDL cells at 3 and 5 days when compared to osteoblasts at equivalent time points $(p<0.05)$.
Fig. 4 PDL cell and osteoblast attachment and proliferation assays for cells seeded on control, blood-adsorbed, and EMD-adsorbed CaP particles. EMD significantly increased PDL cell (a) and osteoblast (b) attachment when compared to blood-adsorbed and control samples. EMD significantly increased primary human PDL cell (c) and osteoblast (d) proliferation at 3 and 5 days post-seeding. Data are means \pm SE. $n=9$ samples from three independent experiments $(p<0.05)$
A)
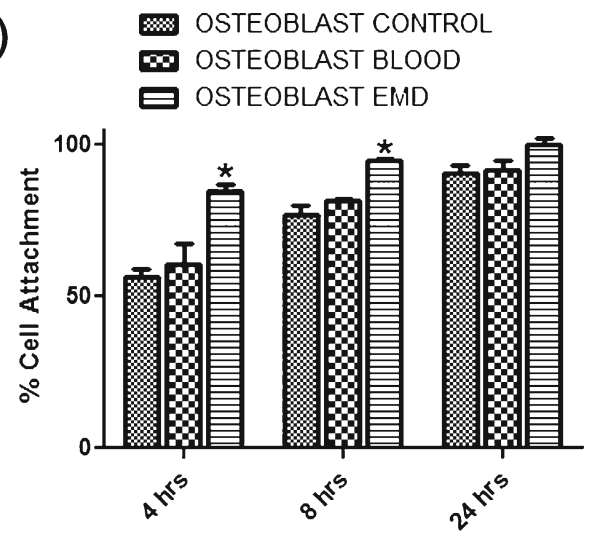

C)

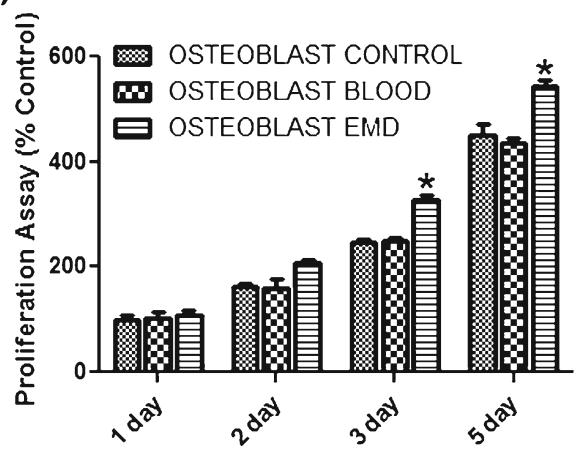

B)

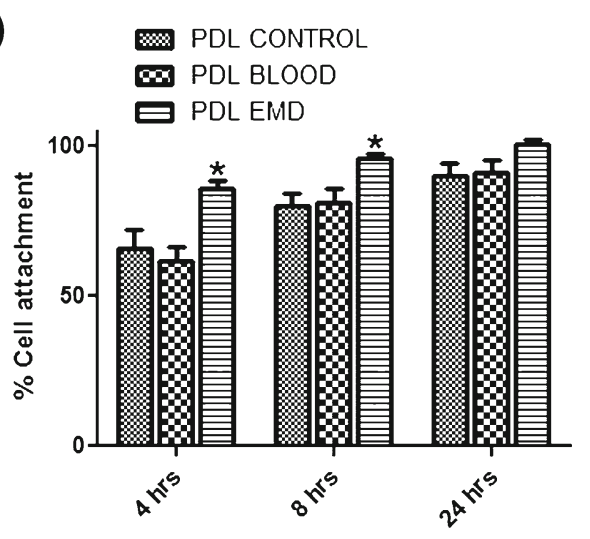

D)

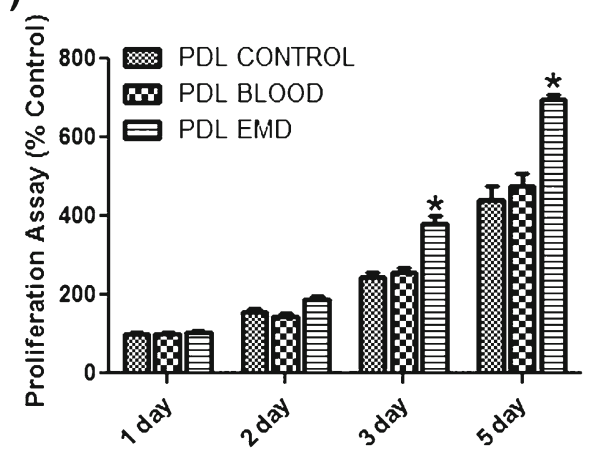



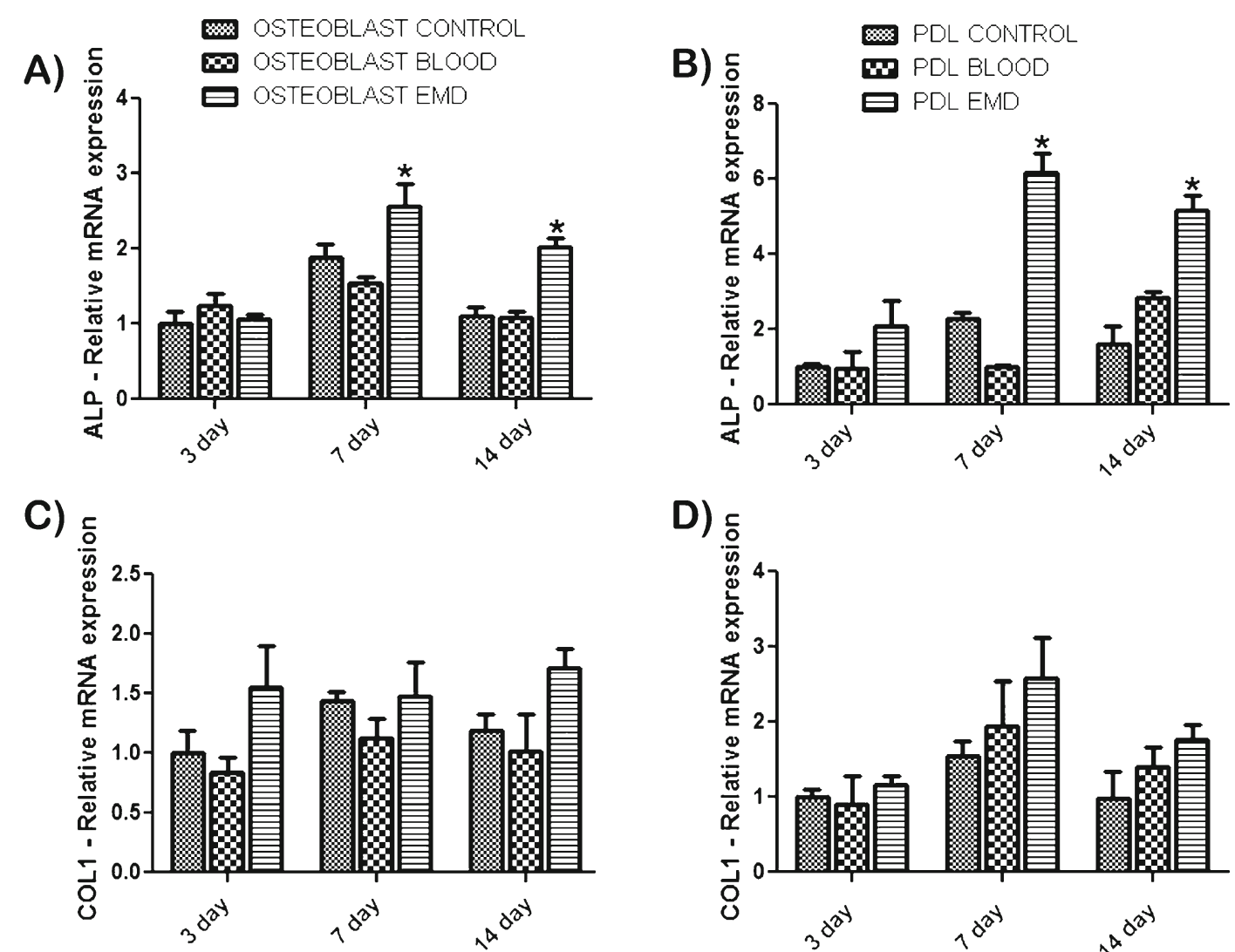

E)

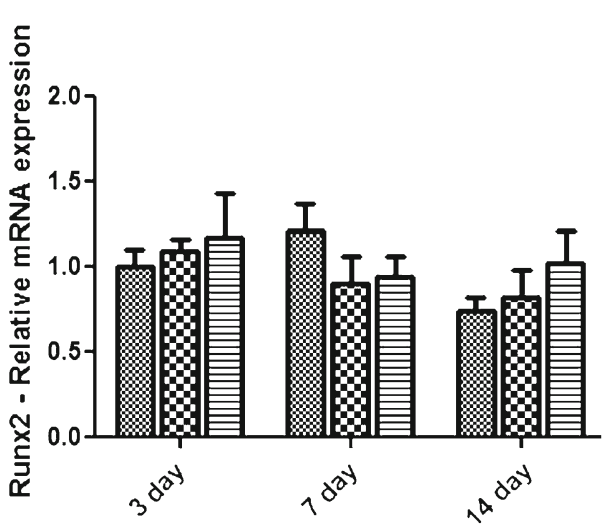

D)

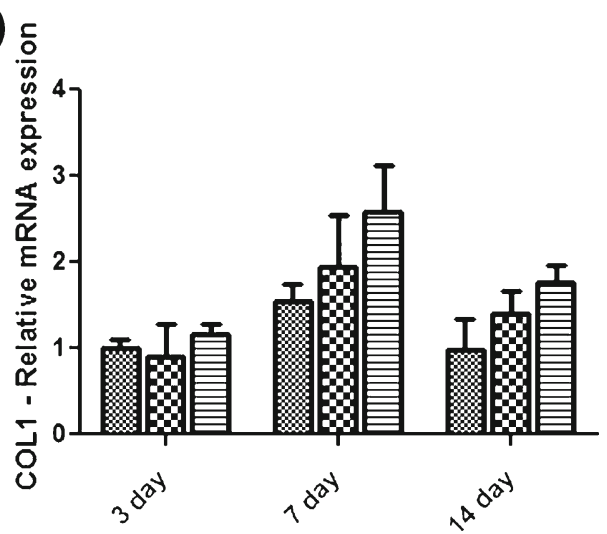

F)
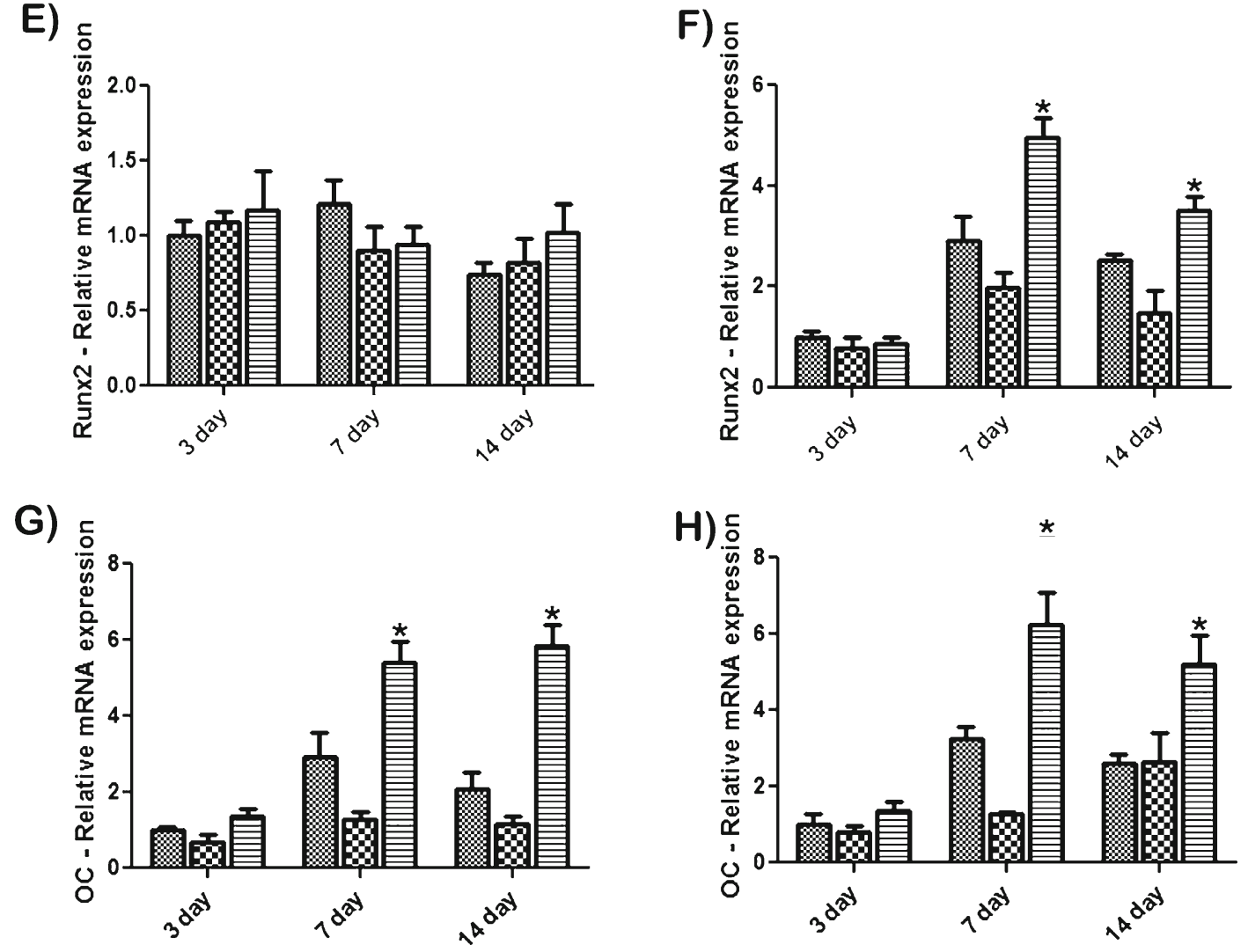

Fig. 5 mRNA levels of osteoblast differentiation markers alkaline phosphatase $(A L P)(\mathbf{a}-\mathbf{b})$, COL1A1 (c-d), Runx2 (e-f), and osteocalcin (OC) $(\mathbf{g}-\mathbf{h})$ for both PDL cells and osteoblasts. EMD

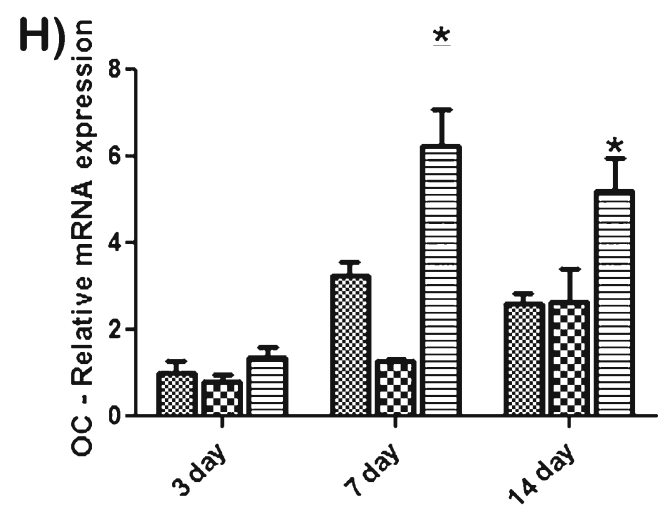

significantly influenced differentiation factors at various time points. Data shown are the average value from three independent experiments (three replicates per experiment $) \pm \mathrm{SE}\left({ }^{*} p<0.05\right)$ 


\section{Osteoblast differentiation}

Primary human osteoblasts and PDL cells were assessed for ALP, COL1A1, Runx2, and OC gene expression at time points 3, 7, and 14 days (Fig. 5). ALP levels were significantly higher on EMD-adsorbed CaP particles at 7 and 14 days postseeding for osteoblasts (Fig. 5a) and PDL cells (Fig. 5b). COL1A1 mRNA levels demonstrated higher, nonsignificant expression at all time points for osteoblast and PDL cells seeded on EMD-adsorbed $\mathrm{CaP}$ particles when compared to control and blood-adsorbed samples (Fig. 5c, d). Analysis of Runx2 gene expression showed significant increases in mRNA levels at both 7 and 14 days post-seeding for PDL cells seeded on EMD when compared to control and bloodadsorbed CaP particles (Fig. 5f). No significant differences were observed for Runx2 gene expression in osteoblasts (Fig. 5e). OC mRNA levels showed significant increases for both PDL cells and osteoblasts seeded on EMD-adsorbed $\mathrm{CaP}$ particles at 7 and 14 days post-seeding when compared to control and blood-adsorbed particles (Fig. 5g, h). In order to further determine the effects of EMD on osteoblast differentiation, mineralization was assessed via alizarin red staining. At 21 days post-seeding, EMD significantly increased alizarin red staining when compared to control and blood-adsorbed particles (Fig. 6).

\section{Discussion}

It was recently demonstrated that a biphasic calcium phosphate sintered at a relatively low temperature has a high ability to promote ectopic bone formation when compared to other synthetic grafting particles [35]. Two main material factors, microporosity and dissolution rate, are suggested to be the reason for the different abilities for synthetic bone grafts to induce ectopic bone formation [35]. The induction of bone formation by $\mathrm{CaP}$ ceramics is thought to be controlled via a secondary mechanism by which $\mathrm{CaP}$ grafts have a high affinity for proteins including bone morphogenetic proteins which are then able to induce bone formation.

In the present study, we tested the ability for $\mathrm{CaP}$ bone grafts to adsorb enamel matrix proteins. EMD is a widely used biologic agent capable of enhancing periodontal wound healing/regeneration [14]. The in vitro roles have been well documented in both osteoblasts and PDL cells [36]. EMD has a significant influence on cell adhesion, cell proliferation, and cell differentiation of many cell types by mediating cell attachment, spreading, proliferation, and survival as well as expression of transcription factors, growth factors, cytokines, extracellular matrix constituents, and other molecules involved in the regulation of bone remodeling [36, 37]. In the present study, it was determined by SEM that EMD readily adsorbed to the surface of $\mathrm{CaP}$ grafting particles and that the protein was readily observed via TEM when an anti-EMD antibody was utilized (Fig. 2a). These results are comparable to those described by Gestrelius et al. who demonstrated that EMD forms insoluble spherical complexes on the surfaces of hydroxyapatite, collagen, and denuded root surfaces [38]. Because $\mathrm{CaP}$ are dense grafting [1] particles, little to no EMD was able to penetrate the interior of these grafting materials. In contrast, we have previously demonstrated that EMD adsorbed onto a natural bone mineral (NBM) was able to adsorb and penetrate into the innermost regions of NBM particles [31]. The ability for EMD adsorption to the innermost regions of a grafting particle to influence cell behavior remains uninvestigated. Further research is also necessary to evaluate the impact of higher/lower macro and micro surface porosity on protein adsorption of EMD and how this may affect downstream cellular pathways.

Following confirmation of protein adsorption of EMD to the surface of the CaP grafting material, we then sought to determine the cellular behavior of osteoblast and PDL cells seeded on CaP particles in the presence or absence of EMD and blood. The major component of EMD, amelogenins, is a family of hydrophobic proteins that account for more than $90 \%$ of the total protein content and has previously been described as a cell adhesion molecule [38]. Several reports have confirmed that other molecules contained in EMD contain integrin-binding regions by demonstrating that PDL cells attach to BSP-like molecules contained in EMD through $\alpha v \beta 3$ integrins [39]. In this study, EMD was able to significantly increase PDL cell and osteoblast attachment to CaP particles at early time points of 4 and $8 \mathrm{~h}$ post-seeding. Furthermore, EMD had a significant influence on cell proliferation and differentiation for both PDL cells and osteoblasts (Fig. 4). Interestingly, higher increases in cell proliferation and differentiation were observed in PDL cells when compared to osteoblasts. These findings are in accordance with Dean et al. who suggested that EMD increases

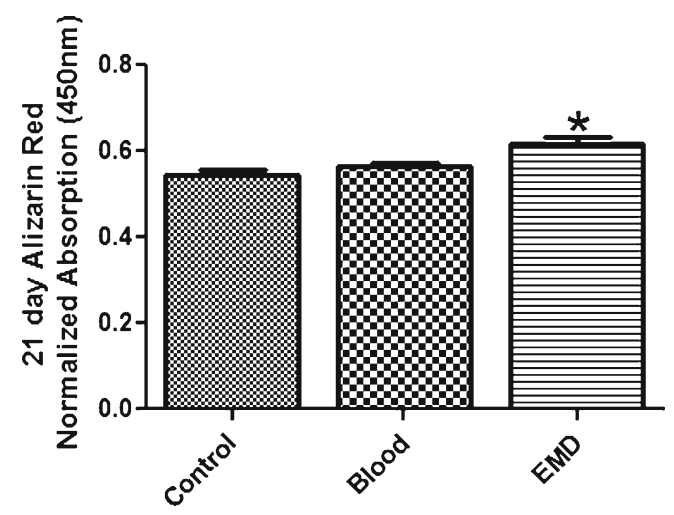

Fig. 6 Alizarin red staining of primary human osteoblasts seeded on control, blood-adsorbed, and EMD-adsorbed CaP particles. EMD significantly increased osteoblast mineralization 21 days post-seeding. Data shown are the average value from three independent experiments (three replicates per experiment $) \pm \mathrm{SE}\left({ }^{*} p<0.05\right)$ 
cell differentiation of mesenchymal cells early in their differentiation process when compared to a more differentiated cell type [40]. Since enamel matrix proteins are embryologically utilized to differentiate cells early in their maturation states prior to root formation, it is logical to assume that EMD as an enamel extract would also have a similar effect on cells with a higher proportion of undifferentiated progenitor cells.

Although previous clinical and animal studies have demonstrated variability among treatment with a combination of grafting particle and EMD, under the present in vitro conditions, EMD was able to stimulate PDL cell and osteoblast attachment, proliferation, and differentiation. Future in vivo and clinical studies are necessary to further elucidate the effects of this combination approach for clinical use.

Acknowledgments The authors gratefully acknowledge the Robert K. Schenk Laboratory of Oral Histology, School of Dental Medicine at the University of Bern, most notably Thuy Tran Nguyen and Monika Aeberhard for their considerable time and valuable insights into the project design. This work was funded by the Department of Periodontology at the University of Bern and Institut Straumann AG (Basel, Switzerland).

Conflict of interest The authors report no conflicts of interest related to this study.

\section{References}

1. Rickert D, Slater JJ, Meijer HJ, Vissink A, Raghoebar GM (2012) Maxillary sinus lift with solely autogenous bone compared to a combination of autogenous bone and growth factors or (solely) bone substitutes. A systematic review. Int J Oral Maxillofac Surg 41(2):160-167. doi:10.1016/j.ijom.2011.10.001

2. Kuhl S, Brochhausen C, Gotz H, Filippi A, Payer M, d'Hoedt B, Kreisler M (2012) The influence of bone substitute materials on the bone volume after maxillary sinus augmentation: a microcomputerized tomography study. Clin Oral Investig. doi:10.1007/s00784-012-0732-2

3. Huang HL, Hsu JT, Chen MY, Liu C, Chang CH, Li YF, Chen KT (2012) Microcomputed tomography analysis of particular autogenous bone graft in sinus augmentation at 5 months: differences on bone mineral density and 3D trabecular structure. Clin Oral Investig. doi:10.1007/s00784-012-0725-1

4. Horvath A, Stavropoulos A, Windisch P, Lukacs L, Gera I, Sculean A (2012) Histological evaluation of human intrabony periodontal defects treated with an unsintered nanocrystalline hydroxyapatite paste. Clin Oral Investig. doi:10.1007/s00784-012-0739-8

5. Pietruska M, Pietruski J, Nagy K, Brecx M, Arweiler NB, Sculean A (2012) Four-year results following treatment of intrabony periodontal defects with an enamel matrix derivative alone or combined with a biphasic calcium phosphate. Clin Oral Investig 16(4):1191-1197. doi:10.1007/s00784-011-0611-2

6. van Hout WM, Mink van der Molen AB, Breugem CC, Koole R, Van Cann EM (2011) Reconstruction of the alveolar cleft: can growth factor-aided tissue engineering replace autologous bone grafting? A literature review and systematic review of results obtained with bone morphogenetic protein-2. Clin Oral Investig 15(3):297-303. doi:10.1007/s00784-011-0547-6
7. Nauth A, Ristevski B, Li R, Schemitsch EH (2011) Growth factors and bone regeneration: how much bone can we expect? Injury 42 (6):574-579. doi:10.1016/j.injury.2011.03.034

8. Browaeys H, Bouvry P, De Bruyn H (2007) A literature review on biomaterials in sinus augmentation procedures. Clin Implant Dent Relat Res 9(3):166-177. doi:10.1111/j.1708-8208.2007.00050.x

9. Jensen T, Schou S, Stavropoulos A, Terheyden H, Holmstrup P (2012) Maxillary sinus floor augmentation with Bio-Oss or Bio-Oss mixed with autogenous bone as graft: a systematic review. Clin Oral Implants Res 23(3):263-273. doi:10.1111/j.16000501.2011.02168.x

10. Miron RJ, Zhang YF (2012) Osteoinduction: a review of old concepts with new standards. J Dent Res 91(8):736-744. doi:10.1177/0022034511435260

11. Yuan H, Yang Z, Li Y, Zhang X, De Bruijn JD, De Groot K (1998) Osteoinduction by calcium phosphate biomaterials. J Mater Sci Mater Med 9(12):723-726

12. Fellah BH, Gauthier O, Weiss P, Chappard D, Layrolle P (2008) Osteogenicity of biphasic calcium phosphate ceramics and bone autograft in a goat model. Biomaterials 29(9):1177-1188. doi:10.1016/j.biomaterials.2007.11.034

13. Yuan H, Fernandes H, Habibovic P, de Boer J, Barradas AM, de Ruiter A, Walsh WR, van Blitterswijk CA, de Bruijn JD (2010) Osteoinductive ceramics as a synthetic alternative to autologous bone grafting. Proc Natl Acad Sci U S A 107(31):1361413619. doi: $10.1073 /$ pnas. 1003600107

14. Sculean A, Alessandri R, Miron RJ, Salvi G, Bosshard DD (2011) Enamel matrix proteins and periodontal wound healing and regeneration. Clin Adv Periodontics 1:101-117

15. Polimeni G, Koo KT, Qahash M, Xiropaidis AV, Albandar JM, Wikesjo UM (2004) Prognostic factors for alveolar regeneration: effect of tissue occlusion on alveolar bone regeneration with guided tissue regeneration. J Clin Periodontol 31(9):730-735. doi:10.1111/j.1600-051X.2004.00543.x

16. Siciliano VI, Andreuccetti G, Siciliano AI, Blasi A, Sculean A, Salvi GE (2011) Clinical outcomes after treatment of noncontained intrabony defects with enamel matrix derivative or guided tissue regeneration: a 12-month randomized controlled clinical trial. J Periodontol 82(1):62-71. doi:10.1902/ jop.2010.100144

17. Aspriello SD, Ferrante L, Rubini C, Piemontese M (2011) Comparative study of DFDBA in combination with enamel matrix derivative versus DFDBA alone for treatment of periodontal intrabony defects at 12 months post-surgery. Clin Oral Investig 15(2):225-232. doi:10.1007/s00784-009-0369-y

18. Hoidal MJ, Grimard BA, Mills MP, Schoolfield JD, Mellonig JT, Mealey BL (2008) Clinical evaluation of demineralized freezedried bone allograft with and without enamel matrix derivative for the treatment of periodontal osseous defects in humans. J Periodontol 79(12):2273-2280. doi:10.1902/jop.2008.080259

19. Intini G, Andreana S, Buhite RJ, Bobek LA (2008) A comparative analysis of bone formation induced by human demineralized freeze-dried bone and enamel matrix derivative in rat calvaria critical-size bone defects. J Periodontol 79(7):1217-1224. doi:10.1902/jop.2008.070435

20. Boyan BD, Weesner TC, Lohmann CH, Andreacchio D, Carnes DL, Dean DD, Cochran DL, Schwartz Z (2000) Porcine fetal enamel matrix derivative enhances bone formation induced by demineralized freeze dried bone allograft in vivo. J Periodontol 71(8):1278-1286. doi:10.1902/jop.2000.71.8.1278

21. Gurinsky BS, Mills MP, Mellonig JT (2004) Clinical evaluation of demineralized freeze-dried bone allograft and enamel matrix derivative versus enamel matrix derivative alone for the treatment of periodontal osseous defects in humans. J Periodontol 75(10):13091318. doi:10.1902/jop.2004.75.10.1309 
22. Rosen PS, Reynolds MA (2002) A retrospective case series comparing the use of demineralized freeze-dried bone allograft and freeze-dried bone allograft combined with enamel matrix derivative for the treatment of advanced osseous lesions. J Periodontol 73 (8):942-949. doi:10.1902/jop.2002.73.8.942

23. Cochran DL, Jones A, Heijl L, Mellonig JT, Schoolfield J, King GN (2003) Periodontal regeneration with a combination of enamel matrix proteins and autogenous bone grafting. J Periodontol 74 (9):1269-1281. doi:10.1902/jop.2003.74.9.1269

24. Yamamoto S, Masuda H, Shibukawa Y, Yamada S (2007) Combination of bovine-derived xenografts and enamel matrix derivative in the treatment of intrabony periodontal defects in dogs. Int J Periodontics Restorative Dent 27(5):471-479

25. Velasquez-Plata D, Scheyer ET, Mellonig JT (2002) Clinical comparison of an enamel matrix derivative used alone or in combination with a bovine-derived xenograft for the treatment of periodontal osseous defects in humans. J Periodontol 73(4):433440. doi:10.1902/jop.2002.73.4.433

26. Zucchelli G, Amore C, Montebugnoli L, De Sanctis M (2003) Enamel matrix proteins and bovine porous bone mineral in the treatment of intrabony defects: a comparative controlled clinical trial. J Periodontol 74(12):1725-1735. doi:10.1902/ jop.2003.74.12.1725

27. Guida L, Annunziata M, Belardo S, Farina R, Scabbia A, Trombelli L (2007) Effect of autogenous cortical bone particulate in conjunction with enamel matrix derivative in the treatment of periodontal intraosseous defects. J Periodontol 78(2):231-238. doi:10.1902/jop.2007.060142

28. Yilmaz S, Cakar G, Yildirim B, Sculean A (2010) Healing of two and three wall intrabony periodontal defects following treatment with an enamel matrix derivative combined with autogenous bone. J Clin Periodontol 37(6):544-550. doi:10.1111/j.1600-051X.2010.01567.x

29. Sculean A, Windisch P, Keglevich T, Gera I (2005) Clinical and histologic evaluation of an enamel matrix protein derivative combined with a bioactive glass for the treatment of intrabony periodontal defects in humans. Int J Periodontics Restorative Dent 25 (2):139-147

30. Sculean A, Windisch P, Szendroi-Kiss D, Horvath A, Rosta P, Becker J, Gera I, Schwarz F (2008) Clinical and histologic evaluation of an enamel matrix derivative combined with a biphasic calcium phosphate for the treatment of human intrabony periodontal defects. J Periodontol 79(10):1991-1999. doi:10.1902/jop.2008.080009

31. Miron RJ, Bosshardt D, Hedbom E, Zhang Y, Haenni B, Buser D, Sculean A (2012) Adsorption of enamel matrix proteins to a bovine derived bone grafting material and its regulation of cell adhesion, proliferation and differentiation. J Periodontol. doi:10.1902/ jop.2011.110480

32. Miron RJ, Gruber R, Hedbom E, Saulacic N, Zhang Y, Sculean A, Bosshardt DD, Buser D (2012) Impact of bone harvesting techniques on cell viability and the release of growth factors of autografts. Clin Implant Dent Relat Res. doi:10.1111/j.17088208.2012.00440.x

33. Miron RJ, Oates CJ, Molenberg A, Dard M, Hamilton DW (2010) The effect of enamel matrix proteins on the spreading, proliferation and differentiation of osteoblasts cultured on titanium surfaces. Biomaterials 31(3):449-460. doi:10.1016/ j.biomaterials.2009.09.075

34. Miron RJ, Hedbom E, Saulacic N, Zhang Y, Sculean A, Bosshardt DD, Buser D (2011) Osteogenic potential of autogenous bone grafts harvested with four different surgical techniques. J Dent Res 90(12):1428-1433. doi:10.1177/0022034511422718

35. Yuan H, van Blitterswijk CA, de Groot K, de Bruijn JD (2006) Cross-species comparison of ectopic bone formation in biphasic calcium phosphate (BCP) and hydroxyapatite (HA) scaffolds. Tissue Eng 12(6):1607-1615. doi:10.1089/ten.2006.12.1607

36. Bosshardt DD (2008) Biological mediators and periodontal regeneration: a review of enamel matrix proteins at the cellular and molecular levels. J Clin Periodontol 35(8 Suppl):87-105. doi:10.1111/j.1600-051X.2008.01264.x

37. Miron RJ, Hedbom E, Ruggiero S, Bosshardt DD, Zhang Y, Mauth C, Gemperli AC, Iizuka T, Buser D, Sculean A (2011) Premature osteoblast clustering by enamel matrix proteins induces osteoblast differentiation through up-regulation of connexin 43 and N-cadherin. PLoS One 6(8):e23375. doi:10.1371/ journal.pone.0023375

38. Gestrelius S, Andersson C, Johansson AC, Persson E, Brodin A, Rydhag L, Hammarstrom L (1997) Formulation of enamel matrix derivative for surface coating. Kinetics and cell colonization. J Clin Periodontol 24(9 Pt 2):678-684

39. Suzuki S, Nagano T, Yamakoshi Y, Gomi K, Arai T, Fukae M, Katagiri T, Oida S (2005) Enamel matrix derivative gel stimulates signal transduction of BMP and TGF-\{beta\}. J Dent Res 84 (6):510-514

40. Dean DD, Lohmann CH, Sylvia VL, Cochran DL, Liu Y, Boyan BD, Schwartz Z (2002) Effect of porcine fetal enamel matrix derivative on chondrocyte proliferation, differentiation, and local factor production is dependent on cell maturation state. Cells Tissues Organs 171(2-3):117-127 